\title{
Medical student impressions of anesthesiology and anesthesiologists
}

\author{
O. Philomena Adudu, MD • Nam H. Le, MD • \\ Isabella Devito, MD · Fiona A. Campbell, MD • \\ Mark F. Levine, MBBCh
}

Received: 12 November 2009/ Accepted: 11 May 2010/Published online: 4 June 2010

(C) Canadian Anesthesiologists' Society 2010

\section{To the Editor,}

Anesthesiology is not top-of-mind amongst medical students when it comes to career decision-making. ${ }^{1-4}$ Within the past ten years of the Canadian Residency Matching System, anesthesiology has consistently ranked outside the top ten most popular residency programs, as defined by the ratio of students applying to their firstchoice program to the quota of available positions. ${ }^{5}$ Recently, we undertook a survey to evaluate the attitudes and perceptions of University of Toronto (U of T) students towards anesthesiology and to identify factors influencing their selection or rejection of the specialty as a career. This insight could facilitate making improvements to the anesthesia curriculum within undergraduate medical education.

After obtaining Research Ethics Board approval, we created the survey using the internet-based services offered by www.surveymonkey.com. We based the survey questions on a previous study and piloted the survey on medical students and anesthesia residents. ${ }^{6}$ Initial contact with all $\mathrm{U}$ of $\mathrm{T}$ medical students was made through the Office of the Dean of Undergraduate Medical Education. Students received an e-mail that included an information letter describing the study, a link to the web-based questionnaire, and particulars regarding the measures used to ensure

O. P. Adudu, MD - F. A. Campbell, MD .

M. F. Levine, MBBCh $(\bowtie)$

The Hospital for Sick Children, University of Toronto,

Toronto, ON, Canada

e-mail: Mark.Levine@ sickkids.ca

N. H. Le, MD

University of Toronto, Toronto, ON, Canada

I. Devito, MD

Mount Sinai Hospital, University of Toronto,

Toronto, ON, Canada confidentiality. Completion of the survey implied consent. Data were collected during the period from October 1, 2007 to December 31, 2007. One reminder was sent four weeks after the start of the study. Demographic data and information regarding year of training and anesthesiology experiences were collected together with respondents' impressions and perceptions of anesthesia and anesthesiologists. We also solicited the ranking preferences, reasons for and against choosing anesthesia as a career, and the value of anesthesia rotations.

Two hundred six (24.2\%) students completed the survey with almost equal representation from each of the four undergraduate years. The female to male ratio was representative of the entire program (60:40). Anesthesia was ranked in the top three career choices by $28.2 \%$ of students, trailing behind internal medicine $(58.7 \%)$, family medicine $(58.3 \%)$, pediatrics $(44.7 \%)$, surgery $(41.7 \%)$, and obstetrics and gynecology $(30.1 \%)$. Interest was lowest in Year 1 (16.9\% of top three choices) and was stable in Years 2, 3, and 4 (34\%, 30.6\%, and 33.3\%, respectively). Top reasons for selecting anesthesia included the scope of practice, practical hands-on experience, broad knowledge incorporation, lifestyle, and acute care nature of the specialty. Top reasons for rejecting the specialty included lack of knowledge or low exposure to anesthesia, boredom, and lack of continuity of care. Most students attributed roles, such as perioperative anesthesia and pain management during labour and delivery, to anesthesiologists, while less than one-third of the students ascribed roles, such as operating room management and expertise in resuscitation, acute/chronic pain management and fluid management, to anesthesiologists. This trend was more prevalent in Years 1 and 2.

Most students (61.6\%) responded that the anesthesia rotation should occur during the third year of the program, 
including $71.4 \%$ of students in Year 4 who had already completed the rotation. Fifty percent of Year 4 students who had not ranked anesthesia in the top three would have considered doing so had they completed an anesthesia rotation before having to make career choices. The aspects rated most highly among the 28 students in Year 4 who had already completed their anesthesia rotations included the value of the skills obtained (85.7\%), hands-on experience (71.4\%), and teaching from faculty (64.3\%). After completing their rotation, $53.6 \%$ of the students believed that anesthesiologists were more important than they had judged previously. Seventeen percent of all respondents believed that their interest level in anesthesia had increased after completion of the survey. This result ranged from a high of $24.1 \%$ in Year 1 students to a low of $9.1 \%$ in Year 4 students.

Limitations of this survey include the low response rate and the fact that the survey was only carried out at one university. The study confirmed that medical students ranked anesthesia low as a career choice, and it identified an inconsistent understanding of the roles of anesthesiologists among the students. This lack of knowledge may be related, in part, to limited and late exposure to the specialty, given the placement of a short rotation in the final year of medical school. Early and lengthier exposure could improve perceptions and attitudes greatly, not to mention provide the opportunity to acquire vital skills and knowledge transferable to other areas of medicine. The resulting mentoring and role modelling could provide students with the proper information to make informed decisions about their careers. Commencing September, 2010 the anesthesia undergraduate rotation at the $\mathrm{U}$ of $\mathrm{T}$ will take place in Year 3 and will run for a full two weeks.

Competing interests None declared.

\section{References}

1. Harvey A, DesCôteaux JG, Banner S. Trends in disciplines selected by applicants in the Canadian resident matches, 19942004. CMAJ 2005; 172: 737.

2. Hutton P, Cooper GM. Editorial II: Careers in anaesthesia. Br J Anaesth 2005; 95: 284-6.

3. Faponle $A F$. Anesthesia as a career-the influence of undergraduate education in a Nigerian Medical School. Niger Postgrad Med J 2002; 9: 11-2.

4. Famewo CE, Bodman RI. The choice of anesthesia as a career by undergraduates in a Saudi university. Middle East J Anesthesiol 1985; 8: 179-85.

5. Canadian Resident Matching Service. Reports \& Statistics - R-1 Statistics. Ottawa (ON); 1997-2008. Available from URL: http:// www.carms.ca/eng/operations_R1stat_e.shtml (accessed May 2010).

6. Adudu OP. What impressions do medical students of the University of Benin have about anaesthesia and anaesthesiologists. Niger Postgrad Med J 2005; 12: 250-4. 